\title{
A criação de um setor de software entre os contextos periférico e semiperiférico: o campo organizacional como um sistema aberto
}

\author{
The creation of a software sector between peripheral and semiperipheral \\ contexts: the organizational field as an open system
}

Luiz Alberto da Costa Mariz

\section{Resumo}

Este artigo focaliza mudanças institucionais incidentes na formação de um campo organizacional de software ancorado numa região periférica. Seu objetivo é descrever essas mudanças e investigar a influência do ambiente institucional no surgimento do campo. É adotado o estudo de caso, pois se trata de um objeto de natureza complexa e peculiar, sendo exploradas insuficiências teóricas no conceito de campo organizacional.

Uma mudança fundamental observada foi o rompimento - por parte dos professores universitários - com a norma da "dedicação exclusiva" (GREENWOOD; SUDDABY; HININGS, 2002) e a outra, a ultrapassagem do limiar da legitimação (ZIMMERMAN; ZEITZ, 2002) das empresas. Enquanto o contexto periférico pareceu propiciar uma maleabilidade institucional na intermediação entre universidade e empresas, 0 ambiente semiperiférico proveu empresas que podem ser consideradas "consumidores empreendedores".

Uma contribuição teórica reside na crítica à conceituação de campo organizacional, segundo a qual seus participantes, a priori, "interagem mais freqüente e decisivamente uns com os outros do que com atores de fora do campo" (SCOTT, apud SCOTT; DAVIS, 2007, p. 118), pois ela tende a obstruir o aprofundamento da análise de um campo que atravessa díspares ambientes institucionais.

Palavras-chave: mudança institucional; campos organizacionais; periferia e semiperiferia; inovação; tecnologia da informação.

Abstract

This research focuses on institutional changes that happened during the formation of a software organizational field on a peripheral region. The objective is to describe these changes and investigate the influence of the institutional environments. The adoption of case study in this research is justified by the complex nature and singularity of the object and the exploration of theoretical shortcomings. One fundamental change observed was the breaking with the professional norm of "exclusive duty" by the university teachers (GREENWOOD; SUDDABY; HININGS, 2002); and another one was the surpassing of legitimacy threshold by the new ventures (ZIMMERMAN; ZEITZ, 2002). While the peripheral context allowed an institutional malleability that seems to have favored the linkage between the university and the firms, the semi-peripheral context facilitated the provision of the "entrepreneurial consumers". A critical appraisal of a concept of organizational field that emphasizes the interactions among the field actors themselves (SCOTT, 1994, p. 207-208) is made because it tends to obstruct a deep analysis of organizational fields that extends through disparate environments.

Key words: institutional change; organizational fields; periphery and semi-periphery; innovation; information technology.

\footnotetext{
${ }^{1}$ Doutor em Administração pela Universidade Federal de Pernambuco - UFPE. Professor do Centro de Pesquisa e Pós-Graduação em Administração (CPPA) da Faculdade Boa Viagem. Endereço: Rua Jacobina, 121/601 - Graças - Recife/Pernambuco - Brasil - CEP: 52011180. E-mail l.a.mariz@uol.com.br

Artigo submetido em abril e aceito em junho de 2008
} 


\section{Introdução}

Este artigo focaliza mudanças institucionais transcorridas durante o recente desenvolvimento do setor de software no estado de Pernambuco. Desde o ano 2000, funciona no Bairro Antigo do Recife, um arranjo empresarial, o Porto Digital, que, com patrocínio do governo estadual e incentivos fiscais da prefeitura, congrega cerca de 120 empresas de tecnologia da informação (TI). Esse arranjo - que pode ser considerado de pequena escala - singulariza-se, no Brasil, por concretizar uma experiência de transferência de tecnologia para o setor produtivo, possibilitando assim o surgimento de empresas locais responsáveis por soluções consideradas inovadoras. Além dessas empresas, nesse setor, articulam-se uma universidade federal "local" e as empresas clientes, sediadas em sua maioria no Sudeste do país. Essencial à formação e ao funcionamento do campo tem sido a atuação do Centro de Estudos Avançados do Recife (Cesar), criado em 1996, o qual pode ser compreendido como um misto de associação profissional de professores universitários, empresa de software e instituto de inovação.

A variedade de organizações participantes dessa experiência transcende as que formam estritamente o setor de software, o que possibilita caracterizar o arranjo interorganizacional como um campo organizacional funcional (SCOTT, 1999). O aumento da cadeia produtiva numa atividade ligada ao conhecimento num estado como Pernambuco (que está no âmago dessa experiência) contraria o papel normalmente reservado às regiões periféricas de se constituírem apenas como fonte de recursos materiais, de mão de obra ou de cérebros para regiões economicamente mais avançadas. Portanto, a existência desse campo constitui um desafio (OLIVER, 1991) à tradicional divisão de trabalho inter-regional, tanto mais quando se considera a dificuldade que tem sido encontrada nas próprias regiões mais adiantadas do país em se desenvolver um arranjo local semelhante, envolvendo universidade e empresas.

Este estudo adota o enfoque institucional, levando em conta as características dos peculiares ambientes institucionais atravessados pelo campo, em especial, os elementos que caracterizam as regiões periféricas e semiperiféricas (RIGGS, 1964). O estudo tem, então, como objetivo, descrever as mudanças institucionais presentes na formação do campo, no quadro da globalização contemporânea, e verificar em que medida aqueles elementos contextuais explicam seu surgimento.

Uma safra recente de trabalhos que toma o campo organizacional como unidade de análise tem adotado, em afinidade com as formulações de Tolbert e Zucker (1999), uma abordagem construcionista, conforme exemplificam os artigos de Greenwood, Suddaby e Hinings (2002), Munir (2005) e Smets (2005). Embora se valendo das definições constitutivas do campo organizacional funcional (SCOTT, 1999), o referencial teórico deste estudo não se atém às interações que se dão estritamente entre os participantes do campo (SCOTT, 1994, apud SCOTT; DAVIS, 2007), mas o toma como uma entidade complexa inserida em ambientes institucionais, podendo em relação a estes comportar-se como um sistema aberto.

\section{A globalização contemporânea e a perspectiva institucionalista}

Na globalização, predominam as trocas desiguais entre países cêntricos e periféricos, tanto nas práticas estatais e econômicas, quanto nas socioculturais. No entanto, a globalização contemporânea singulariza-se, sobretudo, pela constelação de práticas sociais e culturais transnacionais que irromperam "com particular pujança nas últimas décadas" (SANTOS, 2005, p.67).

Santos (2005) distingue duas alternativas de globalização. De um lado, uma globalização hegemônica que se realiza, a partir dos países cêntricos, como difusão de valores e modelos institucionais, adotados por aquiescência, consciente ou inconscientemente, nos países periféricos. De outro, uma globalização contra- 
hegemônica, originada nos países periféricos, constituída de respostas estratégicas que divergem das pressões institucionais prevalecentes.

A globalização hegemônica, por sua vez, desdobra-se em duas "formas de produção". A primeira se dá como localismo globalizado, quando um determinado fenômeno é difundido mundialmente a partir de uma realidade local, como é o caso da difusão do fast food ou da adoção mundial das mesmas leis de propriedade intelectual (SANTOS, 2005, p.65). Como o "global acontece localmente" (Ibidem, p.74), o localismo globalizado impõese ao destino na forma de globalismo localizado, constituído do impacto das práticas e imperativos transnacionais nas condições locais.

Já a globalização contra-hegemônica caracteriza-se como uma luta que visa reverter, em favor dos países e regiões vitimados, os benefícios do aumento das interações transnacionais. Contrapondo-se às trocas desiguais, à exclusão, à inclusão subalterna e à dependência, a globalização contra-hegemônica se configura como uma globalização da resistência. Na globalização contra-hegemônica, buscam-se valores culturais alternativos, por exemplo, com atividades cosmopolitas que articulam resistências localistas, através de movimentos literários, artísticos e científicos.

Uma característica fundamental da teoria institucional é a ênfase no reconhecimento da base social e cultural da influência externa sobre as organizações (HATCH, 2006). Enquanto a vertente do "velho" institucionalismo focaliza a influência do ambiente local sobre uma organização focal (SELZNICK, 1966), a partir do trabalho de Meyer e Rowan (1991), as organizações são concebidas como representações altamente ritualizadas de modelos culturais tomados por verdadeiros, concedendo-se relevo à difusão de tais modelos no interior de campos organizacionais (SUCHMAN; STEWARD; WESTFALL, 2001). Possibilitando a simultânea consideração do "global" e do "local", a complementação dessas características do "velho" e do "novo" institucionalismo habilita a perspectiva institucional na investigação de temas correlatos à globalização, em especial, nesse período em que avulta a constelação de práticas sociais e culturais transnacionais.

Numa manifestação própria da "adolescência" da teoria institucional (SCOTT, 1987), tanto DiMaggio quanto Powell demonstraram insatisfação com as formulações que fizeram juntos num artigo de 1983. Num trabalho que se tornou uma referência importante sobre mudança institucional, DiMaggio (1988) faz uma crítica aberta àquele artigo, indicando como a retórica nele empregada, com expressões como "a jaula de ferro", forçava uma percepção dos seres humanos "como destituídos de poder e inertes em face de inexoráveis processos sociais" (DIMAGGIO, 1988, p. 10).

A contribuição de DiMaggio (1988) para o entendimento dos processos que envolvem a criação de novas instituições visa englobar o universalismo global e as especificidades locais através do conceito de modificação local. Esse autor constata inicialmente que, mesmo já institucionalizada, raramente, a difusão de uma forma organizacional é completa. A institucionalização local de uma nova forma organizacional requer uma reinterpretação da forma original que leve em conta as distribuições de interesses e de posições de barganha dos detentores desses interesses, que variam de local para local. Essa modificação local pode, inclusive, constituir uma fonte de potenciais inovações que, por sua vez, se difundem para outras organizações no campo. Notando como as tentativas de imitar práticas de outras organizações resultam em mudanças involuntárias, Powell (1999) frisa diferenças culturais e resistências, sutis ou abertas, que podem redundar em difusão apenas parcial ou por novas formas, híbridas.

Em convergência com essas formulações, Castells e Hall (2001) admitem que o Vale do Silício é um modelo geral de parque tecnológico que, em princípio, pode ser copiado em qualquer contexto. No entanto, esses autores consideram que algum tipo de adaptação local acontecerá, necessariamente, na adoção desse modelo. Em especial, nas regiões que estão dando os primeiros passos como centros industriais, é indispensável algum tipo de intervenção estatal no processo de criação. 


\section{Em torno do conceito de campo organizacional funcional}

Se podemos considerar que o tema do isomorfismo pioneiramente discutido por DiMaggio e Powell no artigo publicado em 1983 não seja mais hegemônico nas discussões dentro da teoria institucional, o nível de análise do campo, também apresentado para debate no mesmo artigo, manteve ou aumentou sua importância. Segundo DiMaggio e Powell (1991), o campo organizacional é constituído por "aquelas organizações que, em conjunto, constituem um setor reconhecido da vida institucional: fornecedores principais, consumidores de recursos ou produtos, agências reguladoras e outras organizações que produzem serviços ou produtos similares" (Ibidem, p.106). O valor desse nível de análise, para eles, está em focalizar não apenas empresas concorrentes (ou redes de organizações que realmente interagem), mas "a totalidade dos atores importantes" (Ibidem, p.106).

Scott (1992) situa o campo interorganizacional comparativamente com outros dois modelos que envolvem conjuntos de organizações. O modelo de conjunto organizacional, que enxerga o ambiente a partir de uma organização focal, tem a desvantagem de ignorar a natureza do sistema mais amplo de relações, do qual a organização focal é "apenas mais uma participante entre muitas" (Ibidem, p.157). O modelo da população organizacional enfatiza as relações de competição e, com isso, desvia a atenção das relações interorganizacionais cooperativas. Quanto ao nível de análise, o modelo de campo interorganizacional é considerado o mais adequado à análise institucional, pois só ele enfoca o sistema de organizações, com seus elementos, as organizações individuais e a natureza ampla das relações sociais e culturais que elas contraem.

A preferência, nesse último modelo, por relações horizontais dentro de uma área geográfica específica faz com que Scott (1999) proponha a adoção do modelo alternativo de campo organizacional funcional, o qual se estrutura em torno mais de funções do que de determinações geográficas. Nesse modelo se incluem, além do "grupo de organizações que criam produtos ou serviços similares [...], os associados determinantes para suas trocas, as fontes de financiamento, os grupos reguladores [e] as associações profissionais ou comerciais" (SCOTT, 1999, p.226-227). Consideram-se inclusas no campo organizacional funcional, as organizações que estabelecem relações locais e não locais, além de vínculos verticais e horizontais, de natureza cultural, política e técnica.

Ao desenvolver o conceito de campo organizacional, Scott (2001) vai ao ponto de afirmar que esse conceito desafia e suplanta o de ambiente (Ibidem, p.136). No entanto, ponderamos que assumir o nível de análise de campo não implica desconsiderar os ambientes das organizações individuais. Antes, adotar o nível de análise do campo implica um acúmulo de níveis que torna mais complexa a análise institucional. Ocorre nos campos, em especial nos que não se atêm a uma mesma área geográfica, algo semelhante ao que Hatch (2006) identifica numa rede interorganizacional inserida no ambiente global. Para uma determinada organização que se interliga com outras no nível internacional, o ambiente é composto também pelos demais ambientes que são relevantes às outras organizações. A análise no nível do ambiente global ganha em complexidade porque, conforme sintetiza a autora, "o ambiente de uma organização é composto de muitos ambientes inter-relacionados" (Ibidem, p.72).

Ademais, há que se considerar que os próprios campos organizacionais se inserem em ambientes que contêm outros campos organizacionais. A literatura institucional, em geral, trata indiretamente das relações intercampos quando, por exemplo, aborda a questão da definição de fronteiras de uma atividade profissional. Por outro lado, autores que adotam a abordagem da ecologia populacional exploram aspectos das relações institucionais entre populações que podem ser transpostos para as relações entre campos organizacionais. Aldrich e Ruef (2006), por exemplo, observam que novas populações organizacionais são, de certo modo, rodeadas por populações estabelecidas, tornando-se, por isso, vulneráveis a ataques. Organizações pertencentes a essas populações que se sintam ameaçadas podem questionar as bases que estabelecem a conformidade das indústrias nascentes, alterando os termos que ditam o fluxo de recursos para estas. 


\section{Contextos periféricos, semiperiféricos e cêntricos}

Uma reestruturação da teoria marxista da mudança social resultou em conceitos espaciais que vêem o próprio mundo, como um todo, cindido entre "centro" e "periferia" (BURKE, 2002). Nessa concepção, o contraste entre a prosperidade das nações industrializadas e a pobreza dos chamados países "subdesenvolvidos" representam os lados opostos de uma mesma moeda. Wallerstein (1979) considerou que a concepção do sistema-mundo só é compreensível se considerada a existência de uma terceira categoria entre o centro e a periferia: a semiperiferia. Para ele, é indispensável considerar a presença das nações semiperiféricas no sistema mundial, menos por razões estritamente econômicas, do que pelo fato de que elas contribuem com a estabilidade. A existência da semiperiferia significa precisamente que o estrato superior de nações não se defronta com uma oposição unificada de todas as outras, "porque o estrato intermediário é ao mesmo tempo explorado e explorador" (Ibidem, p.23).

Refletindo sobre os processos de institucionalização no contexto brasileiro, quando vigoravam o modelo de substituição de importações e as correlatas concepções desenvolvimentistas, Ramos (1983) debruça-se sobre a especificidade das sociedades semiperiféricas. Apoiando-se em conceitos desenvolvidos por Riggs (1964), Ramos (1983) defende que a análise institucional deve considerar, em primeiro lugar, a função ou contribuição que cabe a uma instituição dar nesse contexto particular. Ele menciona que a família, por exemplo, é uma coisa na sociedade primitiva, outra na sociedade desenvolvida e outra na intermediária. Ele afigura como "mais indicado tomar a função como referência sistemática e examinar quais as estruturas que a realizam" (Ibidem, p.254).

Assim, um adequado estudo das sociedades em transição, segundo Riggs (1964), precisa discernir as diferentes funções que uma estrutura (instituição) pode exercer em diferentes contextos sociais, embora, nominalmente definida da mesma forma. Nelas, coexistem o antigo e o moderno e há uma mistura de elementos urbanos e rurais (RIGGS, 1964). Uma sobreposição institucional faz com que funções sejam formalmente atribuídas a distintas unidades sociais e critérios estritamente estranhos à economia e à política interfiram nessas esferas. A superposição de funções existe em maior grau nas sociedades primitivas, onde o número de estruturas é mínimo, e de forma reduzida, nas sociedades desenvolvidas. A situação nas sociedades em transição é intermediária, com as funções sendo formalmente atribuídas a distintas unidades sociais, mas com interferência de critérios estranhos a sua administração maior do que nas sociedades desenvolvidas (RAMOS, 1983). Embora nominalmente definidas da mesma forma, estruturas sociais situadas em diferentes contextos necessitam de um adequado estudo para se discernir quanto aos diferentes conjuntos de funções realmente exercidos nessas estruturas. Do contrário, incorre-se no "pecado epistemológico" de se chamar pelo mesmo nome coisas com significados diferentes (DAGNINO, 2004).

\section{Método}

Como motivos para a adoção do método de estudo de caso nesta pesquisa, contribuíram tanto o fato de se focalizar o "como" e o "por quê" do objeto investigado (YIN, 1994), quanto a natureza complexa e a peculiaridade desse objeto (MERRIAM, 1998). A profundidade característica desse método tem ainda a vantagem de possibilitar explorar deficiências teóricas (EISENHARDT, 1989), no presente caso, aquelas associadas ao conceito de campo organizacional.

A principal fonte de dados foram entrevistas semi-estruturadas realizadas com diretores, empreendedores, gerentes e professores de várias organizações envolvidas, entre agosto de 2006 e fevereiro de 2007. As principais etapas e linhas de progressão seguidas na parte analítica desta pesquisa estão indicadas na "escada de abstração" mostrada na figura 1.

Inicialmente, a descrição procurou captar a história recente do campo do software em Pernambuco. Em sintonia com o que Patton (2002) identifica na fase de interpretação qualitativa, procurou-se então apreender o caso como um todo, dando vazão à criatividade e ao exercício crítico, visando identificar nos dados o que era 
"realmente importante e significativo" (PATTON, 2002, p.467). Por fim, apresenta-se a conclusão. Mais uma vez recorrendo a Patton (2002), longe de se pretender atingir nessa parte final um "clímax dramático", procurou-se "uma chance de olhar para o futuro" (Ibidem, p.506), visando contribuir com o oportuno debate sobre o conceito de campo organizacional (ver MACHADO-DA-SILVA; GUARIDO FILHO; ROSSONI, 2006).

Para Eisenhardt (1989), o estudo de caso começa com uma quase anulação da teoria preexistente, para, no final da pesquisa, através de comparações com achados de outros estudos, buscar-se o enriquecimento da teoria. De modo semelhante, nesta pesquisa, adotamos um conceito básico de campo organizacional funcional e noções fundamentais da influência dos elementos sociais e culturais do ambiente institucional. Ao final, também estabelecemos comparações, mas não com achados e sim com a versão de conceito de campo organizacional desenvolvida por Scott.

Considerar a influência dos ambientes organizacionais no campo representa uma alteração significativa no entendimento do fenômeno (WHETTEN, 2003) em relação àquela concepção de campo. A introdução do fator "ambiente organizacional" quando se analisa um campo que atravessa os contextos periférico e semiperiférico permite perceber as decisivas influências díspares que nele incorrem.

Figura 1- Progressão da análise

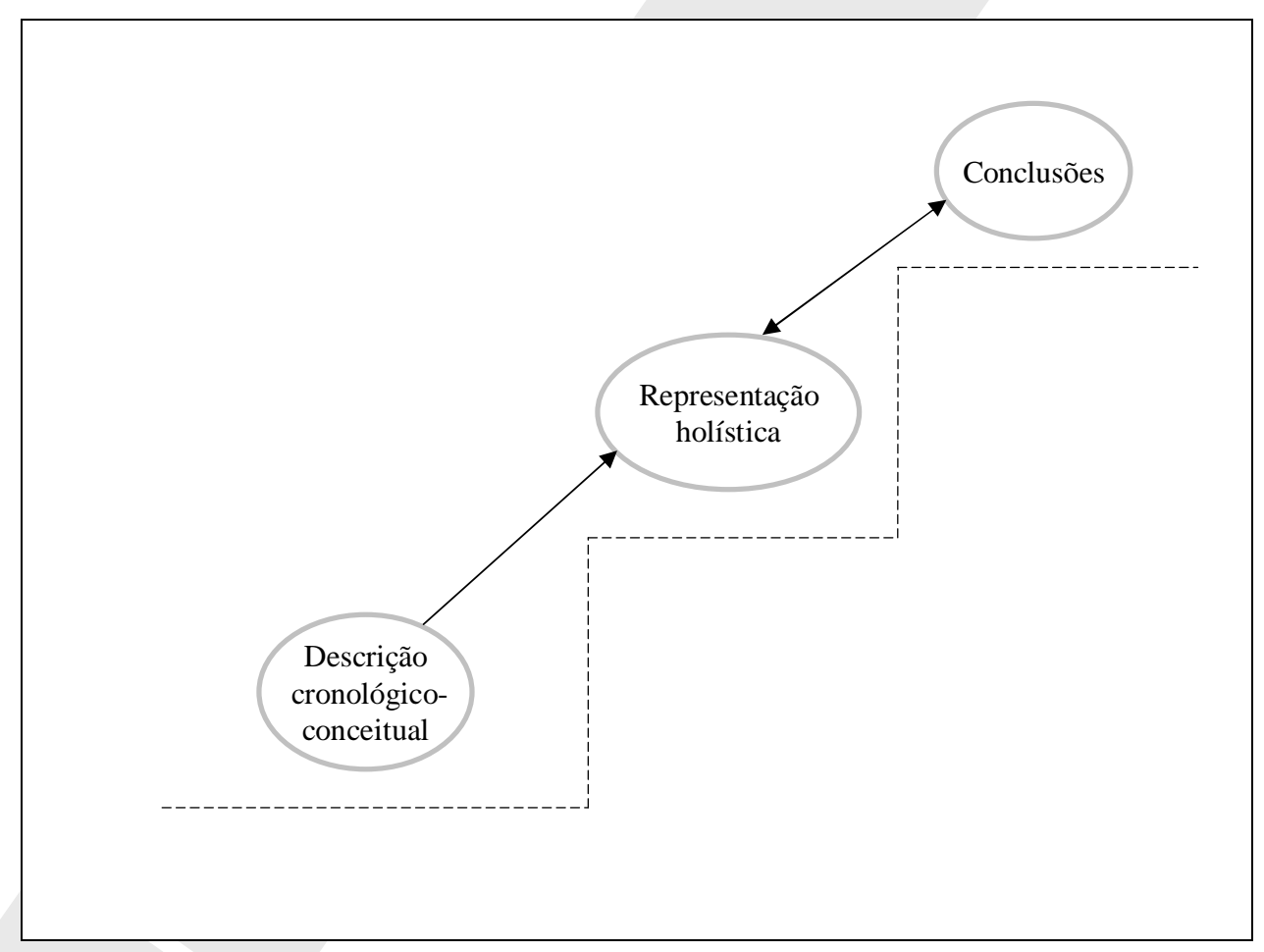

Fonte: adaptado de Carney (apud MILES; HUBERMAN, 1994). 


\section{Descrição}

\section{Mudança local na profissão acadêmica}

No início da década de 1990, pouco depois de o departamento de informática (DI) da Universidade Federal de Pernambuco (UFPE) tornar-se um "departamento acadêmico completo", 70\% de uma turma de graduados foi imediatamente contratada por um banco brasileiro com sede em São Paulo. Esse banco necessitava de pessoal que dominasse uma determinada linguagem de programação, a small talk, que o curso do departamento de informática da UFPE fora o primeiro a ensinar em nível de graduação no Brasil. Uma parte dos graduados também havia sido contratada, como ocorre até hoje, pela Microsoft, para ir trabalhar no desenvolvimento de software na sede dessa empresa, nos EUA.

Esse evento foi interpretado como sinal de que havia "excelência", mas não "relevância", no sentido de que a universidade não estava fazendo diferença significativa para a economia local. O acontecimento teria representado o ponto de inflexão na evolução dessa entidade acadêmica, cujos componentes estavam imbuídos, até então, "unicamente do processo de educação, de pesquisa e de desenvolvimento". É assim que o evento foi teorizado retrospectivamente pelo prof. Silvio Meira, Cientista-Chefe do Cesar:

O que nós estávamos fazendo era criar uma janela de oportunidades para os meninos irem embora. Então, do ponto de vista da economia local, isso era irrelevância social, econômica e, provavelmente, política de imediato, porque a gente ia ajudar a piorar e não ajudar a melhorar. É óbvio que a gente estava criando oportunidades pessoais para muitos, mas para muito menos do que seria possivel se os poucos que estávamos [na Universidade] resolvessem ficar aqui e empreender aqui. Então, essa tomada de decisão, que é uma tomada de decisão que mudou as nossas vidas, mudou, eu acho, o que a universidade fazia aqui. A universidade, pelo menos na área de informática, passou a ter um núcleo de intervenção direta na economia, passou a ter o Cesar. Esse troço precisava de um despertar como aquele.

Conforme Munir (2005), eventos são considerados causadores de mudança, simplesmente, porque são teorizados como tais. Para esse autor, acontecimentos reais podem ser assim interpretados porque já preexiste a intenção de intervir. Assim, o que passa por um evento "exógeno", na realidade, é em grande parte uma "construção social" endógena.

Há evidências de que a essa altura já tivesse ocorrido uma mudança de valores que predispunha os professores a empreenderem negócios com base no conhecimento adquirido. Referindo-se às temporadas vividas por professores nos países cêntricos durante os cursos de pós-graduação, o empresário e professor do Centro de Informática da UFPE (CIn) Merval Jurema, menciona a influência que elas possam ter tido sobre os modelos e valores profissionais em direção à prática da pesquisa aplicada:

O pessoal acha que pesquisa só se faz básica e fundamental [, mas] tem muita pesquisa e muito trabalho aplicado. Então, as pessoas, quando saem, têm essa troca de experiência; vêem e conhecem lá fora. Enfim, foi um processo em que foi amadurecendo essa linha e se percebeu que era o caminho de crescimento que deu certo.

De acordo com o prof. Sílvio Meira, houve, em sequiência, uma infrutífera tentativa de influência junto às empresas locais existentes para que mudassem seu padrão de atuação e de contratação de profissionais:

E aí, a resposta que tinha, obviamente, era a seguinte: “-Esqueça! Nós estamos aqui, nossos clientes daqui não precisam disso." E de nada adiantou a gente dizer: “- Mas os seus clientes que estão aqui hoje não vão estar aqui amanhã. Ou a gente sai para competir nos lugares para onde os nossos alunos estão indo, ou não vai ter empresa local." 
Já na linha de atuação do Cesar, percebe-se a influência de uma visão à qual se converteram "círculos crescentes de professores, pesquisadores, policy makers, funcionários de várias instâncias e áreas de governo, empresários etc." que defendem mecanismos de interação entre a universidade e a empresa (DAGNINO, 2003, p.278). Enquanto, nessa visão, a universidade é compreendida como um agente privilegiado para a "promoção da competitividade das empresas e da nação" (Ibidem, p.271), o modo como isso foi obtido parece representar uma "modificação local" (DIMAGGIO, 1988) Nem sempre se pode assumir como já existentes as empresas com as quais a universidade vai interagir, pois é necessário que antes elas próprias sejam criadas.

Segundo o secretário de Ciência, Tecnologia e Meio Ambiente do Estado de Pernambuco, Claudio Marinho, essa organização viabilizou

situações, para muitos, inconcebíveis, de que o professor de tempo integral e dedicação exclusiva, poderia, e, na realidade, na visão de alguns como a minha, deveria ter, se assim desejasse, um relacionamento com a sociedade, com o setor produtivo, de uma forma mais livre e, portanto, mais contributiva para o desenvolvimento da cidade, da região e do estado.

De acordo com Marinho, os professores universitários sofrem impedimentos de toda ordem, principalmente, quanto ao nível dos valores internos da universidade: "o preconceito quanto à possibilidade de ser também um ente privado, alguém que também pode ter empresa, que pode tratar de negócios". Marinho considera que "a coisa mais inovadora" do Cesar é a forma como os professores procuraram diluir as pressões sobre as atividades empresariais de que eles próprios pudessem participar. A solução encontrada foi conceber o Cesar como uma organização que pode atuar como se fosse uma empresa, mas cujos lucros "serão, obrigatoriamente, reinvestidos no desenvolvimento de suas próprias atividades".

Expandindo os limites da profissão para agora incluir a possibilidade de empreender novos negócios, o Cesar atua como uma agência representativa que conforma e redefine as práticas apropriadas do acadêmico, exercendo um dos principais papéis identificados por Greenwood, Suddaby e Hinings (2002) numa associação profissional. O Cesar pode ser caracterizado como um instituto de inovação, uma incubadora de empresas e fábrica de software (GOULART, 2005). No entanto, como atua nessas frentes no interesse dos professores universitários - e, além disso, defende a modificação dos limites da profissão acadêmica -, o entendemos como uma associação profissional com várias funções.

A orientação empreendedora do Cesar reside nas oportunidades que proporciona aos professores e alunos do seu Centro de Informática (CIn) de empreenderem negócios ou prestarem serviços no mercado, sem comprometimento do vínculo "exclusivo" que mantêm com a universidade. É essa acomodação que Marinho parece identificar como "uma artimanha" empresarial do Cesar, diante da necessidade dessa organização de contratar "dezenas de jovens professores para desenvolver produtos". O caso do Cesar parece se aproximar de um dos modos de empreendedorismo coletivo considerados por Johannisson (1998), que envolve a fundação de uma associação profissional, tendo como principal objetivo proteger a liberdade individual de cada empreendedor.

Segundo o prof. Sílvio Meira, "metade dos professores do Centro de Informática, de uma forma ou de outra, está envolvida com o Cesar". No estatuto do Cesar consta a exigência de que apenas professores do CIn possam assumir sua diretoria, além do compromisso de se investir no próprio Centro de Informática e de a este serem revertidos os recursos disponibilizados com a sua eventual extinção. A participação dos professores e as condições estatutárias fazem do Cesar uma espécie de representação do CIn, um empreendedor representativo da coletividade de professores.

Trata-se, ademais, de um empreendedorismo reflexo ou de um "metaemprendedorismo", de acordo com termo adotado por Etzioni (1987) para designar um tipo especial de empreendedorismo, encontrado, por exemplo, em think tanks ou em projetos colaborativos de P\&D entre universidades e empresas. Quando uma organização empreendedora que atua em ambientes de rápidas mudanças torna-se obsoleta, é típico que uma das suas subunidades assuma iniciativas de mudança na própria estrutura da organização, visando adotar novos padrões. 
O projeto geral dos professores pode ser interpretado como uma modificação local das prescrições, difundidas globalmente, de aproximação entre a universidade e as empresas. No caso de uma região periférica cujas empresas não absorviam os graduados numa universidade com currículo de conteúdo avançado, a promoção da relação universidade/empresa significou, antes do estabelecimento da relação, a própria criação das empresas e, ainda, a preparação dos próprios empreendedores, a maioria deles, professores ou alunos universitários.

O diretor do CIn, prof. Paulo Cunha, formulou comparações qualitativas diretas com alguns dos outros grandes centros de ensino e pesquisa de TI no Brasil, que contribuem para ressaltar importantes peculiaridades do centro pernambucano. Essas peculiaridades constituem indícios que ajudam a elucidar como foi possível criar um parque tecnológico numa região relativamente atrasada, enquanto outros centros (inclusive, mais adiantados) não conseguem fazê-lo.

Para Cunha, o CIn, talvez, seja o melhor quando se considera o conjunto das atividades científicas e de inovação, pois nesse centro logrou-se criar um ambiente eclético que, quer alguém tivesse mais inclinação para atuar como profissional, quer como acadêmico, não necessitaria abandonar a região em busca de uma graduação ou pós-graduação de qualidade. Segundo ele, já o Instituto de Informática da Universidade de São Paulo (USP), por exemplo, é um departamento puramente acadêmico, de grande excelência, que se apóia essencialmente na matemática, mas não realiza nenhuma interação com empresas. Esse instituto forma, apenas, cerca de um doutor por ano, em média, o que, apesar da boa produção de pesquisa e publicação, compromete a avaliação geral.

No caso do departamento da Universidade Federal de Minas Gerais (UFMG), o destaque é dado à grande ligação com empresas, em especial com a Telemar. Já o modelo do Curso de Computação da Universidade Federal do Rio Grande do Sul (UFRGS) seria, segundo ele, muito parecido com o da UFPE, no sentido de "formar não só qualidade, mas também quantidade", promovendo, ainda, interação com empresas, embora, sem a mesma importância estratégica que o CIn da UFPE tem para a região onde atua.

Considerar o Centro de Informática de Pernambuco como melhor do ponto de vista do "conjunto" parece indicar um aspecto importante da análise institucional em regiões menos desenvolvidas. É que parece haver, nesse caso, uma maior superposição de funções. Sendo mais especializadas nas regiões mais desenvolvidas, as organizações existem aí em maior variedade e, portanto, apenas nominalmente são as organizações das regiões menos desenvolvidas definidas da mesma forma, pois, na realidade, sendo menos especializadas, tendem a abranger um conjunto maior de funções (RAMOS, 1983; RIGGS, 1964). Esse acúmulo de funções numa mesma unidade pode explicar a mais fácil interação "universidade/empresa" entre organizações como o CIn e o Cesar - surgidas de um processo de diferenciação de um mesmo departamento acadêmico -, ao contrário do que se observa, por exemplo, em São Paulo. Segundo um professor da USP, apesar de São Paulo ser a cidade que mais produz software no Brasil, "há dez anos tentamos construir aqui, sem sucesso, algo como o Cesar" (DOAÇÃO DE..., 2006, p.8).

\section{Um parque tecnológico na periferia da semiperiferia}

Sobre uma questão relacionada à mudança do campo do software em Pernambuco, não parece haver importantes discordâncias. Trata-se do modo simbólico conforme decorreu a montagem inicial do Porto Digital. De acordo com Valério Veloso, presidente do Núcleo de Gestão do Porto Digital (NGPD) desde 2005, a criação do Porto Digital começou "por trás", isto é, com exceção da infra-estrutura e da tentativa de atrair as primeiras empresas, o marketing veio à frente das principais atividades operacionais.

Corroborando essa constatação, Sílvio Meira apresenta uma interpretação construcionista do processo:

A gente fez muito mais marketing do que no começo a gente tinha para oferecer. E aí, uma vez que você tenha criado a idéia de que é possivel, torna-se possível porque as pessoas acreditam que é, e aí você cria a realização da possibilidade. Então, esse mecanismo de venda, de construção do 
imaginário, e a partir desse imaginário, a concretização dos processos que levam aos resultados prometidos, é o que eu acho que a gente fez também de diferente.

Segundo Veloso, a estratégia inicial consistiu essencialmente na projeção da "marca Porto Digital" junto ao "público-alvo", os principais mercados brasileiros na área de informática: o de empresas privadas, em São Paulo, e o de órgãos públicos, em Brasília. Foi contratada uma empresa "de altíssima competência", especializada em assessoria e consultoria de comunicação e marketing, com experiência na área de TI.

Veloso faz referência ao episódio conhecido entre os promotores do Porto Digital como o paradoxo de Chico Science, o músico pernambucano que somente ficou conhecido em Recife e no Brasil depois que cerca de 10 mil pessoas foram assisti-lo num show no Central Park, em Nova York. Do mesmo modo, a expectativa dos promotores do Porto Digital era a de que "quando o pessoal de São Paulo começar a dizer que a gente é bom, a gente vai ter atenção".

A concepção do Porto Digital, à primeira vista, bem que poderia ser tomada por um dos casos de aplicação de uma "fórmula mágica" de criação de parques tecnológicos, criados em regiões pelo mundo afora, obedecendo ao "apressado estudo de algum consultor oportunista" (CASTELLS; HALL, 2001, p.28). No entanto, há evidências de que ela foi sucedida por realizações tangíveis.

O preconceito contra empresas nordestinas que atuam na parte inovadora do software é ilustrado pelas primeiras experiências de uma empresa especializada na área de segurança computacional, a Tempest, incubada no Cesar e que hoje tem contratos com empresas de médio e de grande porte, conforme depoimento de Evandro Hora, um dos seus sócios:

Nós cansamos de perder negócios. Pegar o avião e ir lá [em São Paulo], toda semana, mostrar. O cara adorava, as empresas adoravam. "Rapaz, que maravilha, não tem ninguém aqui fazendo isso, me dá o seu cartão... Ah, vocês são lá de Recife, né?”.[...] Acabava de perder o negócio quando ele via que a empresa estava sediada em Pernambuco.

Um curioso expediente adotado por sugestão de um profissional tarimbado e que surtiu efeito, segundo Hora, foi o de inverter, no cartão de visitas da empresa, a posição dos nomes das cidades onde existem escritórios, colocando "São Paulo" no lado esquerdo e "Recife" no direito, sugerindo com isso que a sede se localizava na primeira cidade.

Uma experiência semelhante foi descrita por outro dirigente de empresa de software também incubada no Cesar. Referindo-se à campanha de lançamento da marca "Porto Digital" em 2003 (cerca de três anos após a constituição oficial desse arranjo produtivo), Fred Vasconcelos, dirigente da JYNX - uma empresa que desenvolve vários tipos de jogos para computador - narra sua experiência em relação ao preconceito existente contra empresas nordestinas de TI:

Eu tive muita dificuldade há 4 anos atrás, quando eu entrava em São Paulo. [...] O cara não consegue imaginar que no Nordeste - que na cabeça dele é o fim do mundo do sertão, totalmente seco - existam empresas que trabalhem com alta tecnologia.

Ele prossegue, descrevendo a mudança de comportamento ocorrida com o surgimento do Porto Digital:

[...] eu tive mais acesso, mais facilidade. Nós passamos a ser melhor recebidos. Pessoas que comumente batiam a porta, vamos dizer assim, na cara da gente, passaram a nos respeitar mais, a escutar o que a gente tinha para dizer e o que a gente tinha para mostrar. Então, começamos a ter mais cliente.

A "invenção" virtual do Porto Digital parece ter contribuído com a mudança de arraigadas crenças de um público nacional que é decisivo para o estabelecimento de contratos na área de TI. Assim, pelo menos, algumas 
empresas pernambucanas atuantes no setor - em especial, as localizadas no Porto Digital - puderam ter sua capacidade reconhecida, e a partir daí passarem a auferir resultados concretos.

Uma das dificuldades básicas para quem intenta desenvolver uma empresa baseada em inovação numa região periférica reside na grande carência de capital de risco de origem local. No caso dos produtos inovadores, entende-se que a relativa exigüidade de recursos das empresas compradoras da própria região periférica torna o mercado local "muito conservador". A situação é diversa numa cidade como São Paulo, equiparada por Vasconcelos a centros como Nova York, Paris, São Francisco, Miami ou Cincinnati, que constituem "tubulações por onde o dinheiro, as decisões e o desenvolvimento efetivo do país passam". Referindo-se a empresas ambientadas nessas cidades, ele afirma:

Elas tendem a ser menos conservadoras, tendem a arriscar mais. E elas têm capital para arriscar. Esse é o ponto. Elas têm como. Eu enxergo isso claramente hoje. Por que as empresas aqui são mais conservadoras? Porque elas têm menos recursos, elas não podem se dar ao luxo de arriscar tanto. Então, tem muito disso. Com algumas exceções, evidentemente, mas, basicamente, é socioeconômica a razão pela qual as empresas de tecnologia têm que passar por lá.

$\mathrm{Na}$ ausência de outra forma de fomento, as empresas compradoras é que terminaram por exercer o papel de fomentadoras. Temos aqui, portanto, uma ilustração do papel exercido na economia moderna pelo que Metcalfe (2003) denomina de "consumidor empreendedor".

Contrariando o senso comum, a condição periférica é vista por Silvio Meira, um dos principais personagens atuais do campo da TI em Pernambuco, como uma vantagem para a realização de empreendimentos inovadores, no que tange às instituições:

Às vezes a gente quer se entender como centro, mas Recife é uma localidade periférica. É um lugar periférico, num país periférico. [...] Ser periférico, ao contrário do que possa parecer, tem vantagens também. Quer dizer, tem um conjunto de coisas que você pode fazer na periferia, exatamente, porque é periferia. Tem um monte de coisas que nós fizemos aqui, consideradas, hoje, nacionalmente, inovadoras; e nós só conseguimos fazer em Recife porque era aqui. Nós não teríamos conseguido fazer em São Paulo ou no Rio, ou em outros lugares, porque lá, já têm estruturas de poder para inovação e negócios mais consolidadas e mais duras. Inovação e criação de novas instituições e organizações têm muito a ver com a flexibilidade, com a maleabilidade do arranjo social ao seu redor.

\section{Análise}

\section{Mudanças institucionais no campo}

Na figura 2 são representadas as principais organizações do campo em estudo e os respectivos ambientes em que baseiam suas operações. A parte propriamente produtiva encontra-se no próprio estado de Pernambuco. A universidade tem na realidade um contexto tríplice, pois, além de pertencer ao sistema federal de ensino superior e pesquisa, opera numa região periférica e, como as grandes universidades, de modo geral, vincula-se ao ambiente global em que circula o conhecimento universal. Nas atividades de desenvolvimento de software, como fornecedoras de novos produtos ou provedoras de soluções tecnológicas ad hoc, figuram variadas organizações: pequenas e médias empresas, além do Cesar, uma organização multifuncional sem fins lucrativos Completando a cadeia, vêm as empresas-cliente que, em sua maioria, são organizações brasileiras ou subsidiárias de empresas multinacionais, sediadas nos centros dinâmicos da economia brasileira e que, por isso, são consideradas parte de um ambiente semiperiférico.

Em linhas tracejadas, estão indicadas na figura 2 as principais mudanças institucionais que propiciaram a montagem da cadeia de inovação. Os primeiros passos dados para a formação de um setor local de software, sintonizado com os recentes avanços da informática, pareceram marcados por ações intencionais decorrentes da 
elaboração de um projeto profissional. Diante da inércia das empresas locais em se adaptarem às mudanças da Terceira Informática, fase dessa tecnologia centrada na utilização de microcomputadores e na Internet (BRETON, 1991), os próprios professores empreenderam um projeto empresarial. Isso implicou, em primeiro lugar, criar as próprias empresas ou, até mesmo, antes delas, os agentes capazes de criá-las. Em segundo lugar, implicou completar a teia de relações da cadeia produtiva do software que, além da universidade a que já pertencem os professores, inclui outros agentes e organizações essenciais, como clientes, organizações de apoio e o Estado.

$\mathrm{Na}$ primeira mudança, os próprios professores criaram condições para se constituírem como acadêmicos empreendedores, fundando paralelamente uma entidade, o Cesar - que incuba empresas e realiza projetos sob encomenda - ambas, atividades com participação dos corpos docente e discente. Essencial na consecução desse projeto foi a redefinição dos limites da profissão do acadêmico de nível superior, o que ocorreu com o rompimento da norma da "dedicação exclusiva", que inibia a participação dos acadêmicos na criação de empresas baseadas no próprio conhecimento especializado ou em projetos de consultoria.

Na medida em que visou capacitar o próprio corpo de professores e alunos na tarefa de criação de empresas e em se constituir ele próprio como um instituto de inovação, o Cesar pode ser compreendido como uma associação profissional. Expandindo os limites da profissão para, agora, incluir a possibilidade de empreender novos negócios, o Cesar atua como uma agência representativa que conforma e redefine as práticas apropriadas do acadêmico, exercendo um dos principais papéis identificados por Greenwood, Suddaby e Hinings (2002) numa associação profissional. Conforme ressaltam esses autores, através do discurso que legitima o ajuste nas práticas de uma profissão, as associações profissionais exercem o papel de agentes de mudança de um campo. Essa constatação contraria muitos relatos institucionalistas que vêem nessas entidades "agências conservadoras" (Ibidem, p.76), responsáveis pela persistência das práticas já institucionalizadas.

Na segunda mudança institucional, o conjunto das empresas de Pernambuco se beneficiou de recursos estatais, provenientes da privatização de uma distribuidora de energia elétrica, para obtenção de ampla legitimidade coletiva. É que, com esses recursos, foi possível deflagrar uma construção social, fundada num trabalho profissional de marketing, que ensejou a ultrapassagem de "um certo limiar" de legitimação característico das empresas novatas (ZIMMERMAN; ZEITZ, 2002, p. 417), revertendo o já mencionado preconceito existente nos principais mercados do Brasil em relação a empresas nordestinas atuantes na área de tecnologia. Também se registraram interações de algumas das empresas, individualmente, no sentido de promoverem seus produtos inovadores junto a potenciais usuários. Trata-se de uma espécie de "autodescoberta" das empresas locais como nova fonte de suprimento para um mercado que já funcionava, exercendo-se assim um dos cinco tipos de inovação tipificados por Schumpeter (1950).

Figura 2 - Modificações nos ambientes periférico e semiperiférico 


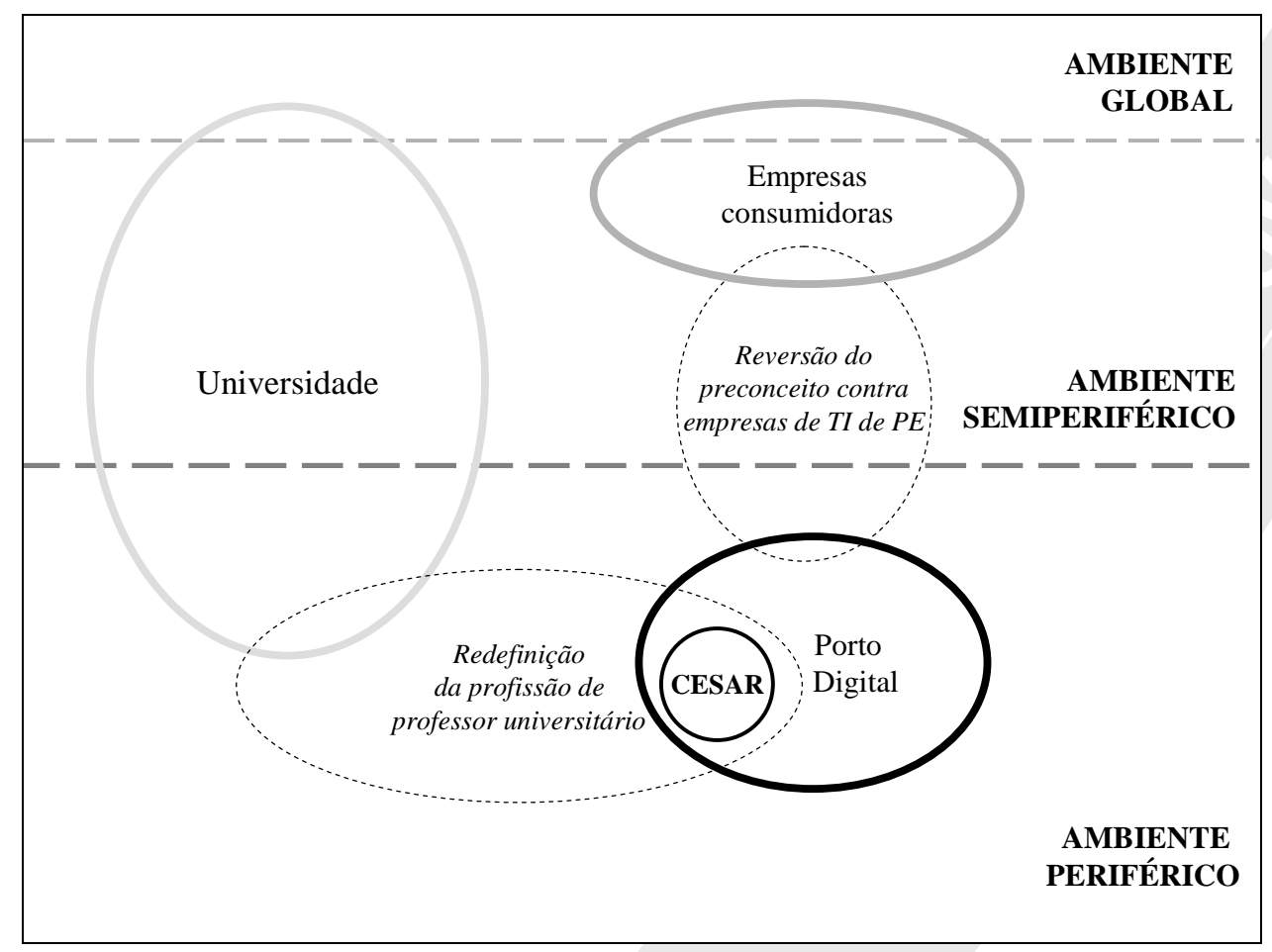

Fonte: elaboração do autor

\section{Contextualização do campo organizacional}

Procuramos sintetizar, no quadro 1, as evidências encontradas sobre as influências dos ambientes institucionais periférico e semiperiférico nas partes do campo e no campo como um todo. Na ponta do consumo, parece clara a maior propensão dos "consumidores empreendedores" à inovação. As empresas locais - em especial, as empresas inovadoras nascentes - , puderam então se beneficiar de contratos com essa categoria de clientes, intrinsecamente difícil de existir em regiões periféricas, mas não nos mais afluentes ambientes semiperiféricos ou cêntricos. 


\section{Quadro 1- Influências dos ambientes institucionais}

\begin{tabular}{ccc} 
& Mercado & Interação $\boldsymbol{U}$ - $\boldsymbol{E}$ \\
\hline Periferia & Conservador & Maleabilidade institucional \\
\hline Semiperiferia & Presença de consumidores \\
& empreendedores” & Grande especialização funcional \\
\hline
\end{tabular}

Fonte: elaboração do próprio autor

Além do provimento de recursos essenciais, a universidade semiperiférica, estando inserida numa sociedade periférica, parece mais apta ao exercício do papel de intermediação entre a pesquisa e a sua aplicação prática, pois está imersa num contexto de maior "maleabilidade institucional". Há indicações de que essa universidade seja um caso singular no Brasil, pois logrou reunir, num determinado momento da sua trajetória, um conjunto heterogêneo de acadêmicos com altas e variadas qualificações, desde o ensino e a pesquisa até o empreendedorismo. Por outro lado, obtiveram-se evidências de que semelhante reunião de habilidades heterogêneas numa mesma organização parece menos plausível de ocorrer nos centros mais desenvolvidos do Brasil. Portanto, excluindo o consumo, esse conjunto de acadêmicos estava em condições de, ao menos, iniciar o exercício das funções da inovação: invenção, aplicação e intermediação. É como se parte substancial do campo local do software tivesse sido "incubada" no interior dessa organização acadêmica.

Em acréscimo, a maior "maleabilidade institucional" propiciada pela região periférica significa menor resistência à inovação, pois praticamente inexistem localmente outras "estruturas de poder e de negócios mais consolidadas", como as que existem, por exemplo, em meios mais adiantados como São Paulo ou Rio de Janeiro, muitas delas ligadas ao velho paradigma industrial. Quando da mudança de paradigma tecnológico, essas antigas vantagens podem se transformar em empecilhos custosos de serem removidos (PEREZ; SOETE, 1988). Portanto, o caso parece ilustrar que um ambiente periférico, de certo modo, pode ter essa outra vantagem de prescindir (ou de reduzir) a necessidade do trabalho destruidor que, na visão de Schumpeter (1950), está intrinsecamente presente nos processos de inovação.

\section{Conclusão}

O objeto em análise foi caracterizado como uma espécie de campo organizacional funcional do campo mundial de software, que cruza os ambientes periférico, semiperiférico e global. No centro desse campo, estão a geração ou o acesso à informação tecnológica nova e valiosa, uma mão de obra altamente qualificada e capital de risco - elementos que configuram uma cadeia de inovação típica (CASTELLS; HALL, 2001) -, enquanto no mercado consumidor verificamos a existência de empresas que exercem o papel de "consumidores empreendedores". Em outra função considerada essencial para uma cadeia de inovação, a de instituição intermediária (DODGSON, 2005), destaca-se o Cesar. Esse centro liga regularmente o trabalho de pesquisa da universidade às necessidades das empresas-cliente, além de terceirizar para pequenas e médias empresas locais, parte das atividades dos contratos que firma.

No entanto, o conceito de cadeia de inovação por si só não abrange todas as relações fundamentais do campo de software em Pernambuco, pois nele não estão incluídas outras relações igualmente essenciais para a existência desse campo. Deste também fazem parte agentes organizacionais que foram decisivos para sua estruturação. É o caso do Cesar, que, na qualidade de associação profissional, promoveu o empreendedorismo 
como uma das possíveis atribuições de um professor universitário de "dedicação exclusiva", estabelecendo condições para o surgimento de inovadoras empresas de TI na região. Numa segunda fase, o governo estadual passou a patrocinar e a participar ativamente de uma campanha promocional do parque tecnológico do Porto Digital junto aos principais centros compradores nacionais, contribuindo assim para impulsionar a formação do campo.

Portanto, é a articulação das organizações mais estritamente ligadas à cadeia da inovação com as demais organizações caracterizadoras do campo organizacional funcional - "as fontes de financiamento, os grupos reguladores [e] as associações profissionais ou comerciais" (SCOTT, 1999, p.226-227) - que viabiliza a formação e o regular funcionamento do campo organizacional de software, de cuja parte produtiva participam organizações de Pernambuco.

As interações construcionistas no interior do próprio campo explicam uma parte das mudanças que conduziram à sua formação. Contudo, é a natureza dos contextos periférico e semiperiférico, e a sua complementaridade, que efetivamente parecem explicar a participação de organizações cruciais ao arranjo. Assim, em superposição aos processos interacionistas internos ao campo, o estudo revela que nele preexistiam elementos históricosociais "decisivos", que contribuem para explicar não apenas características fundamentais do campo, mas a sua própria existência.

Parte dos agentes do campo organizacional tende a atribuir a existência deste ao empreendedorismo de alguns indivíduos que estiveram à frente de várias mudanças. Embora não se possa subestimar a agência desses indivíduos, nesse ponto, o máximo que o estudo pode sugerir é que o ambiente institucional influi indiretamente no grau de empreendedorismo.

Nossa contribuição teórica parece estar na crítica a um influente conceito de campo organizacional, segundo o qual seus participantes "interagem mais freqüente e decisivamente uns com os outros do que com atores de fora do campo" (SCOTT, 1994 apud SCOTT; DAVIS, 2007, p.118). Essa conceituação coaduna-se com formulações do mesmo autor, segundo as quais, conceitos como o de campo organizacional desafiam e suplantam o de ambiente (SCOTT, 2001, p.136).

A nosso ver, subjaz a essa conceituação de Scott, a noção de campo como um sistema fechado. É certo que, do mesmo modo que com as organizações isoladas, alguns campos organizacionais serão empiricamente mais abertos ou mais fechados. Porém, operacionalizar o conceito, a priori, como um sistema fechado parece limitar de saída o aprofundamento da investigação.

Preferimos conceber o campo organizacional como uma espécie de rede interorganizacional complexa, sujeita à intervenção dos vários ambientes específicos das organizações que o constituem (HATCH, 2006). Desse modo, parece ser possível aprofundar a compreensão de aspectos fundamentais de um campo que, como o que foi aqui estudado, atravesse díspares ambientes. 


\section{Referências}

ALDRICH, Howard, RUEF, Martin. Organizations evolving. 2. ed. London: SAGE, 2006.

BRETON, Phillipe. História da Informática. São Paulo: Editora UNESP, 1991.

BURKE, Peter. História e teoria social. São Paulo: Editora da Unesp, 2002.

CASTELLS, Manuel; HALL, Peter. Tecnópolis del mundo: la formación de los complejos industriales del siglo XXI. Madri: Alianza Editorial, 2001.

DAGNINO, Renato. A relação universidade-empresa no Brasil e o "argumento da hélice tripla". Revista Brasileira de Inovação, v.2, n.2, p.267-307, jul./dez. 2003.

A relação pesquisa-produção: em busca de um enfoque alternativo. In: SANTOS, Lucy et al (Org.). Ciência, tecnologia e sociedade: o desafio da interação. Londrina: Iapar, 2004.

DiMAGGIO, P. Interest and agency in institutional theory. In: ZUCKER, L. G. (Ed.). Institutional patterns and organizations. Cambridge, MA: [s.n.], 1988.

; POWELL, W. The iron cage revisited: institutional isomorphism and collective rationality in organizational fields. In: POWELL, W.; DiMAGGIO, P. The new institutionalism in organizational analysis. Chicago: University of Chicago Press, 1991.

DOAÇÃO DE cérebros. Informática Hoje. São Paulo, outubro 2006, p. 6-11.

DODGSON, Mark. As políticas para ciência, tecnologia e inovação nas economias asiáticas de industrialização recente. In: KIM, Linsu; NELSON, Richard. Tecnologia, aprendizado e inovação: as experiências de economias de industrialização recente. Campinas: Unicamp, 2005.

EISENHARDT, K. Building theories from case study research. Academy of Management Review, v.14, n.4, p.532-550, 1989.

ETZIONI, Amitai. Entrepreneurship, adaptation and legitimation: a macro-behavioral perspective. Journal of Economic Behavior and Organization. v. 8, p. 175-189, 1987.

GOULART, Sueli. Sobre a interferência da produção científica e tecnológica da universidade no desenvolvimento local: o caso da Ciência da Computação. Tese de Doutorado - Programa de Pós-Graduação em Administração da Universidade Federal de Pernambuco, Recife, 2005.

GREENWOOD, R.; SUDDABY, R.; HININGS, C. R. Theorizing change: the role of professional associations in the transformation of institutionalized fields. Academy of Management Journal, v.45, n.1, p.58-80, 2002.

HATCH, Mary Jo (with CUNLIFFE, Ann). Organization theory: modern, symbolic and postmodern perspectives. New York: Oxford University Press, 2006.

JOHANNISSON, Bengt. Entrepreneurship as a collective phenomenon. RENT XII, Lyon, 26-27 Novembro de 1998.

MACHADO-DA-SILVA, C.; GUARIDO FILHO; ROSSONI, L. Campos organizacionais: seis diferentes leituras e a perspectiva de estruturação. Revista de Administração Contemporânea, v.10, 2006. Edição Especial.

MERRIAM, S. B. Qualitative research and case study applications in education. São Francisco: Jossey-Bass Publishers, 1998.

METCALFE, Stan. The entrepreneur and the style of modern economics. In: Seminário Brasil em Desenvolvimento. Rio de Janeiro: 2003. 
MEYER, J. W.; ROWAN, B. Institutionalized organizations: formal structure as myth and ceremony. In: POWELL, W.; DiMAGGIO, P. The new institutionalism in organizational analysis. Chicago: University of Chicago Press, 1991.

MILES, M. B., HUBERMAN, A. M. Qualitative data analysis: an expanded sourcebook. 2. ed. Thousand Oaks: Sage, 1994.

MUNIR, Kamal. The social construction of events: a study of institutional change in the photografic field. Organization Studies, v.26, n.1, p.93-112, 2005.

OLIVER, Christine. Strategic responses to institutional processes. Academy of Management Review, v.16, n.1, p.145179, Jan. 1991.

PATTON, M. Q. Qualitative research and evaluation methods. [S.I.]: Sage, 2002.

PEREZ, Carlota, SOETE, Luc. Catching-up in technology: entry barriers and windows of opportunity. In: DOSI, G. et al (Ed.). Technical change and economic theory. London: Pinter, 1988.

POWELL, W. Expansión del análisis institucional. In: POWELL, W., DiMAGGIO, P. El nuevo institucionalismo en el análisis organizacional. México: Fondo de Cultura Económica, 1999.

RAMOS, A. G. Administração e contexto brasileiro: esboço de uma teoria geral da administração. 2.ed. Rio de Janeiro: Fundação Getulio Vargas, 1983

RIGGS, F. W. Administration in developing countries: the theory of prismatic society. Boston: Houghton Mifflin, 1964. SANTOS, Boaventura. Os processos da globalização. In: A globalização e as ciências sociais. 3.ed. São Paulo: Cortez, 2005.

SCHUMPETER, Joseph A. Capitalism, socialism and democracy. New York: Harper and Brothers, 1950.

SCOTT, W. R. The adolescence of institutional theory. Administrative Science Quarterly, v.32, n.2, p.493-511, dez. 1987.

. The organizations of environments: network, cultural, and historical elements. In: MEYER, J. W.; SCOTT, W. R. (Ed.). Organizational environments: ritual and rationality. Newbury Park: Sage, 1992.

. Retomando los argumentos institucionales. In: POWELL, W.; DiMAGGIO, P. El nuevo institucionalismo en el análisis organizacional. México: Fondo de Cultura Económica, 1999.

. Institutions and organizations. 2.ed. Thousand Oaks: Sage, 2001.

; DAVIS, G. F. Organizations and organizing: rational, natural and open system perspectives. Upper Saddle River: Pearson, 2007.

SELZNICK, P. TVA and the grass roots. New York: Harper and Row, 1966.

SMETS, Michael. Micro-processes of field construction: evidence from a global law firm. In: EGOS - COLÓQUIO ALEMANHA, 21., Alemanha/Berlim. Anais... Alemanha/Berlim: EGOS/Colloquium, 2005.

SUCHMAN, M.; STEWARD, D.; WESTFALL, C. The legal environment of entrepreneurship. In: SCHOONHOVEN, C.; ROMANELLI, E. (Ed.). The entrepreneurship dynamic. Stanford: Stanford University Press, 2001.

TOLBERT, P.; ZUCKER, L. A institucionalização da teoria institucional. In: CLEGG, S.; HARDY, C.; NORD, W. Handbook de estudos organizacionais. São Paulo: Atlas, 1999. v.l.

WALLERSTEIN, Immanuel. The capitalist world-economy. Cambridge/Paris: Cambridge University Press/Maison des Sciences de I'Homme, 1979. 
WHETTEN, David. O que constitui uma contribuição teórica? Revista de Administração de Empresas, São Paulo, v.43, n.3, p.69-73, jul./set. 2003.

YIN, R. K. Case study research: designs and methods. 2.ed. Thousand Oaks: Sage, 1994.

ZIMMERMAN, M.; ZEITZ, G. Beyond survival: achieving new venture growth by building legitimacy. Academy of Management Review, v.27, n.3, p.414-431, jul. 2002. 